\title{
Predictive factors of cytotoxic damage in radioactive iodine treatment of differentiated thyroid cancer patients
}

\author{
SATORU MONZEN $^{1}$, YASUSHI MARIYA ${ }^{1}$, ANDRZEJ WOJCIK ${ }^{2}$, CHIKA KAWAMURA $^{1}$, \\ AYUMI NAKAMURA ${ }^{1}$, MITSURU CHIBA ${ }^{3}$, MASAHIRO HOSODA ${ }^{1}$ and YOSHIHIRO TAKAI ${ }^{4}$ \\ ${ }^{1}$ Department of Radiological Life Sciences, Division of Medical Life Sciences, Hirosaki University \\ Graduate School of Health Sciences, Hirosaki, Aomori 036-8564, Japan; ${ }^{2}$ Centre for Radiation Protection Research, \\ MBW Department, Stockholm University, SE-106 91 Stockholm, Sweden; ${ }^{3}$ Department of Biomedical Sciences, \\ Division of Medical Life Sciences, Hirosaki University Graduate School of Health Sciences, \\ Hirosaki, Aomori 036-8564; ${ }^{4}$ Department of Radiology and Radiation Oncology, Hirosaki \\ University Graduate School of Medicine, Hirosaki, Aomori 036-8562, Japan
}

Received November 24, 2014; Accepted January 22, 2015

DOI: $10.3892 / \mathrm{mco} .2015 .499$

\begin{abstract}
Radioactive iodine $\left({ }^{131} \mathrm{I}\right)$ therapy in patients suffering from differentiated thyroid cancer (DTC) is a targeted treatment commonly used for thyroid ablation and locoregional and distant metastatic spread management. Despite a significant proportion of the ${ }^{131} \mathrm{I}$ dose entering the circulation, there is currently no detailed information regarding its effect on the blood cell system. In order to assess the cytotoxic effects of ${ }^{131} \mathrm{I}$ therapy on the circulatory system, blood cell levels, thyroid-related hormones and $\mathrm{CD} 45^{+}$cell cytotoxicity were estimated in blood collected from patients with DTC. The micronuclei $(\mathrm{MN})$ frequency of the peripheral blood $\mathrm{CD} 45^{+}$ cell fraction was significantly increased after 30 days of ${ }^{131}$ I therapy compared to that prior to treatment, although a strong individual variation was observed. A significantly negative correlation between MN frequency and the level of platelets and plateletcrit was observed; however, there was no such correlation with thyroid-related hormones. These results suggest that the correlation between $\mathrm{MN}$ frequency and the platelet system may serve as a biomarker of exposure and, possibly, of sensitivity in DTC patients undergoing ${ }^{131} \mathrm{I}$ therapy following thyroid and lymph node surgery.
\end{abstract}

\section{Introduction}

Differentiated thyroid cancer (DTC) patients are at increased risk of distant metastases and locoregional recurrence. The

Correspondence to: Dr Satoru Monzen, Department of Radiological Life Sciences, Division of Medical Life Sciences, Hirosaki University Graduate School of Health Sciences, 66-1 Hon-cho, Hirosaki, Aomori 036-8564, Japan

E-mail: monzens@cc.hirosaki-u.ac.jp

Key words: predictive factors, cytotoxic damage, radioactive iodine therapy, differentiated thyroid cancer, micronuclei standard therapy for DTC is radioactive iodine $\left({ }^{131} \mathrm{I}\right)$ administration into the bloodstream in order to induce thyroid ablation and manage locoregional and metastatic spread $(1,2)$. Although ${ }^{131} \mathrm{I}$ accumulates in the thyroid gland, the patient's entire body is exposed to highly energetic $\beta$ - and $\gamma$-radiation as a consequence of its decay in the gland, during its transport to the thyroid gland and its excretion through the kidneys. The known adverse effects of ${ }^{131} \mathrm{I}$ therapy are inflammation, such as sialadenitis and the subsequent reduction of normal tissue function, such as xerostomia $(3,4)$.

Peripheral blood (PB) comprises plasma and circulating cells; leukocytes are a particularly radiosensitive blood component $(5,6)$. The cytogenetic effects of ${ }^{131}$ I on PB lymphocytes have been analyzed (7-12). Generally, an increased frequency of chromosomal aberrations and micronuclei (MN) was observed following treatment, although often only at the overall patient group and not at the individual patient level. However, how ${ }^{131} \mathrm{I}$ treatment affects the functionality of the whole blood cell system, as well as the intercorrelation between the various changes, has not been fully elucidated.

Thyroglobulin ( $\mathrm{Tg}$ ), thyroid-stimulating hormone (TSH), free triiodothyronine (fT3) and free thyroxine (fT4) levels in PB serum are generally monitored during iodine treatment and allow a crude estimate of the condition of each DTC patient. The cellular components of the human hematopoietic system exhibit different sensitivities to radiation $(13,14)$; therefore, an analysis of the effect of iodine treatment on their levels is of particular interest. The aim of the present study was to investigate the effect of iodine treatment on the extent of cytogenetic damage in lymphocytes and on the composition of the hematopoietic system, thyroid-related hormones and CD45 cell cytotoxicity.

\section{Materials and methods}

Study population. A total of 15 DTC patients (mean age \pm standard deviation, $56 \pm 11$ years) who were treated at the Hirosaki University Hospital between December, 2012 
and August, 2014, were enrolled in the present study. The clinical characteristics of the study population are summarized in Table I. All the patients underwent thyroid and lymph node surgery followed by treatment with ${ }^{131} \mathrm{I}$. Depending on the stage of the disease, an activity of $3.7 \mathrm{GBq}$ (stage T1-T3, 10 patients) or $5.5 \mathrm{GBq}$ (stage T4, 5 patients) was administered after 2 weeks of thyroid hormone replacement and iodine restriction (Fig. 1).

This study was approved by the Committee of Medical Ethics of the Hirosaki University School of Medicine, Hirosaki, Japan (no. 2013-025) to ensure the welfare and privacy of the donors. Following a detailed verbal explanation regarding the content of this study, written informed consent was obtained from each of the patients.

Collection of PB and isolation of cells and serum. PB was collected from the patients using heparin lithium tubes and serum separation tubes (BD Biosciences, Franklin Lakes, NJ, USA). The serum and buffy coat were separated and light-density mononuclear PB cells were further separated from the buffy coat by centrifugation for $30 \mathrm{~min}$ at $200 \mathrm{x} \mathrm{g}$ on a cushion of Lymphosepar I $(1.077 \mathrm{~g} / \mathrm{ml}$; Immuno-Biological Laboratories Co., Ltd., Fujioka, Japan) and washed thrice in magnesium/calcium-free phosphate buffered saline.

Calculation of $P B$ cells. The total number of light-density mononuclear viable cells and the expression of $\mathrm{CD} 45^{+}$cell surface antigen were analyzed by direct immunofluorescence flow cytometry (Aria SORP; BD Biosciences).

Cytokinesis-block micronucleus (CBMN) assay. The CBMN assay was conducted on the basis of the recommendations of the International Atomic Energy Agency (15). In brief, 1x10 ${ }^{6}$ mononuclear cells were placed in a 60-mm cell culture dish (Corning Life Sciences, Falcon, New York, NY, USA) containing RPMI-1640 medium (Life technologies, Tokyo, Japan) with $10 \%$ fetal bovine serum (Japan Bioserum, Fukuyama, Japan) and $2 \%$ phytohemagglutinin (PHA; GE Healthcare, Fairfield, CT, USA). The cultures were incubated for $70 \mathrm{~h}$ at $37^{\circ} \mathrm{C}$ in a humidified atmosphere of $95 \%$ air $/ 5 \% \mathrm{CO}_{2}$. At 24 h post-PHA stimulation, cytochalasin-B $(6 \mu \mathrm{g} / \mathrm{ml}$; Sigma-Aldrich, Tokyo, Japan) was added to the culture and the cells were harvested after a further $46 \mathrm{~h}$. Harvesting was performed by washing the cells with methanol and staining with a Hoechst 33342 solution ( $1 \mu \mathrm{g} / \mathrm{ml}$; Sigma-Aldrich). The evaluation was conducted using a fluorescence/bright-field microscope at x400 magnification (IX71; Olympus, Tokyo, Japan).

Quantitative analysis of PB cell components and thyroid-related hormones. The different $\mathrm{PB}$ cells [white blood cells (WBCs), red blood cells (RBCs), platelets (PLT), neutrophils and lymphocytes], hemoglobin $(\mathrm{Hb})$ and hematocrit value (Ht), were analyzed using the automated hematology system XE-5000 (Sysmex, Kobe, Japan). The thyroid-related hormones (TSH, fT3, fT4) and Tg were analyzed using the Cobas 6000 (e 601) analyzer (Roche Diagnostics, Tokyo, Japan).

Radiation dosimetry. The radiation dose rate at the skin adjacent to the thyroid gland was measured by RadEye calibrated pocket survey meter (Thermo Scientific Inc., Waltham, MA, USA).
Table I. Clinical characteristics of the study population.

\begin{tabular}{lc}
\hline Characteristics & $\begin{array}{c}\text { Patient no. } \\
(\mathrm{n}=15)\end{array}$ \\
\hline Gender (female/male) & $10 / 5$ \\
Age, years & \\
Range & $39-76$ \\
Mean \pm standard deviation & $56 \pm 11$ \\
$\mathrm{TNM}$ classification & \\
$\mathrm{T}_{1-3} / \mathrm{T}_{4}$ & $10 / 5$ \\
$\mathrm{~N}_{0} / \mathrm{N}_{1}$ & $10 / 5$ \\
$\mathrm{M}_{0} / \mathrm{M}_{1}$ & $13 / 2$ \\
Radioactivity (3.7/5.5 GBq) & $10 / 5$ \\
Race (ethnicity) & Asian (Japanese)
\end{tabular}

Statistical analysis. Statistical analysis was performed using the Origin software package (Pro version 9.0; OriginLab Corporation, Northampton, MA, USA) and SPSS version 17.0 (IBM, Chicago, IL, USA) for Windows. Data were compared using the Spearman's rank correlation test, Wilcoxon signed-rank test, analysis of variance and Mann-Whitney $\mathrm{U}$ test. $\mathrm{P}<0.05$ was considered to indicate a statistically significant difference.

\section{Results}

Variation of thyroid-related hormones. Thyroid-related hormones in PB serum of DTC patients were quantified prior to (day 0) and after (day 30) treatment with ${ }^{131} \mathrm{I}$. Prior to treatment, the median values of fT3 and fT4 were 0.75 and $1.9 \mathrm{pg} / \mathrm{ml}$, respectively, and increased by 3.7-fold $\left(\mathrm{P}=1.2 \times 10^{-4}\right)$ and 8.1 -fold $\left(\mathrm{P}=1.2 \times 10^{-4}\right)$, respectively, by day 30 post-treatment (Fig. 2A and B). By contrast, the levels of TSH (median, $94.4 \mu \mathrm{IU} / \mathrm{ml}$ ) and $\mathrm{Tg}$ (median, $26.4 \mathrm{ng} / \mathrm{ml}$ ) decreased by 0.084 -fold $\left(\mathrm{P}=6.10 \times 10^{-5}\right)$ and 0.15 -fold $\left(\mathrm{P}=1.22 \times 10^{-4}\right)$, respectively, by day 30 (Fig. $2 \mathrm{C}$ and $\mathrm{D}$ ). A strong individual variability in response was observed, whereas no clear association was observed between the extent of the effect and the applied iodine activity.

Leukocyte analysis. The concentrations of different PB cells were estimated. The WBC count (median on day $0,7.4 \times 10^{3} / \mu 1$ ) and $\mathrm{RBC}$ count (median on day $0,5.0 \times 10^{6} / \mu 1$ ) decreased by 0.74 -fold $\left(\mathrm{P}=1.22 \times 10^{-4}\right)$ and 0.90 -fold $\left(\mathrm{P}=2.32 \times 10^{-3}\right)$, respectively, by day 30 (Fig. 3A and B). The number of neutrophils (median on day $0,4.3 \times 10^{3} / \mu 1$ ) and lymphocytes (median on day $0,2.3 \times 10^{3} / \mu 1$ ), which constituted the major bulk of WBCs, significantly decreased by 0.79 -fold $\left(\mathrm{P}=2.14 \times 10^{-3}\right)$ and 0.62 -fold $\left(\mathrm{P}=6.10 \times 10^{-5}\right)$, respectively, by day 30 compared to day $0\left(4.3 \times 10^{3} / \mu 1\right.$ and $2.3 \times 10^{3} / \mu 1$, respectively) (Fig. 3C and D). Furthermore, the PLT level decreased 0.70 -fold $\left(\mathrm{P}=1.22 \times 10^{-4}\right)$ by day 30 compared to that on day 0 (median, $2.45 \times 10^{5} / \mathrm{ml}$ ) (Fig. 3E).

The corpuscular components and/or indices in PB were also analyzed. The median levels of $\mathrm{Hb}$ and $\mathrm{Ht}$ decreased by 0.92 -fold $\left(\mathrm{P}=2.81 \times 10^{-3}\right)$ and 0.93 -fold $\left(\mathrm{P}=1.53 \times 10^{-3}\right)$, 


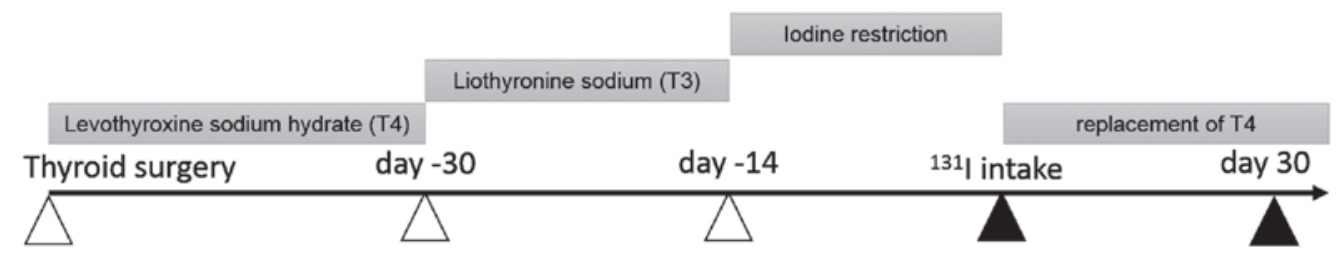

Figure 1. Schematic representation of the therapeutic design in this study. Following thyroidectomy, the patients were administered thyroid hormone replacement therapy, namely free triiodothyronine (T3) and free thyroxine (T4). Iodine-131 $\left({ }^{131} \mathrm{I}\right)$ treatment was initiated after a pause period of administrating thyroid hormones and iodine restriction for 2 weeks. Peripheral blood samples were collected immediately prior to and 30 days after ${ }^{131}$ I treatment (₫).
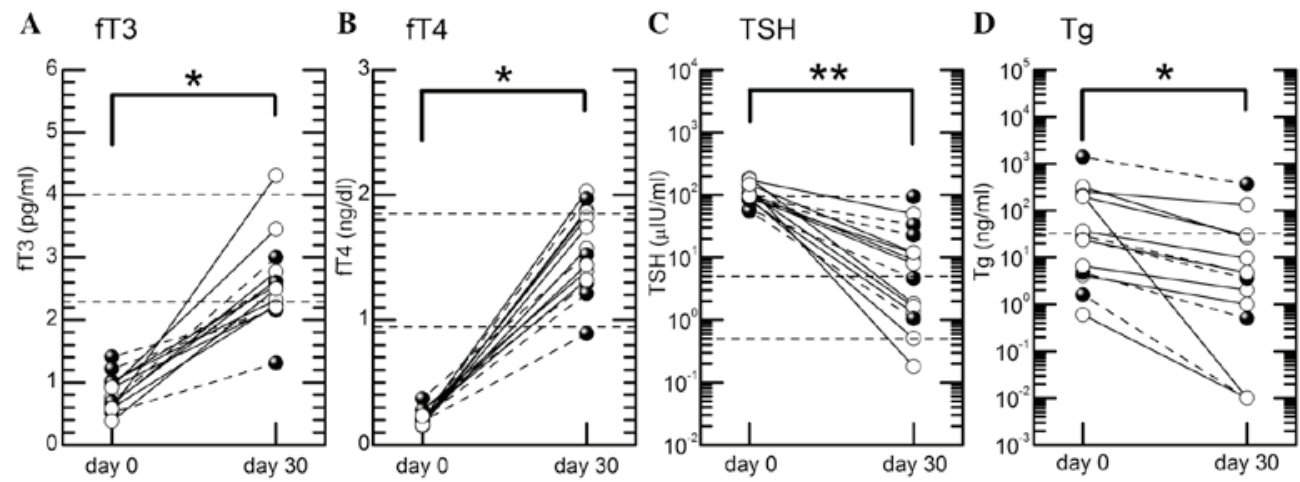

Figure 2. Evaluation of thyroid-related hormones. The (A) free triiodothyronine (fT3), (B) free thyroxine (fT4), (C) thyroid-stimulating hormone (TSH) and (D) thyroglobulin ( $\mathrm{Tg}$ ) of individual patients were quantified on days 0 and 30. Dotted line, normal range. White and black circles, patients administered 3.7 and $5.5 \mathrm{GBq}$, respectively. ${ }^{*} \mathrm{P}=1.22 \times 10^{-4}$ and ${ }^{* *} \mathrm{P}=6.10 \times 10^{-5}$ by Wilcoxon single-rank test.

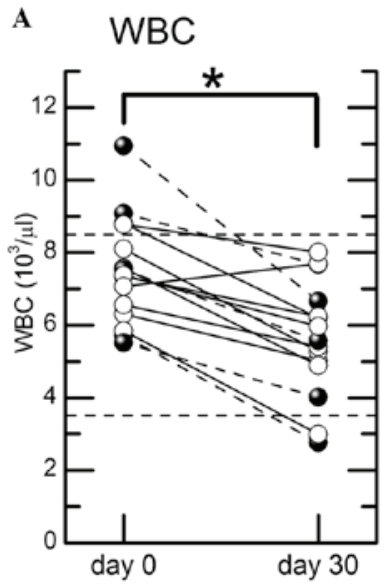

B $\quad \mathrm{RBC}$

C
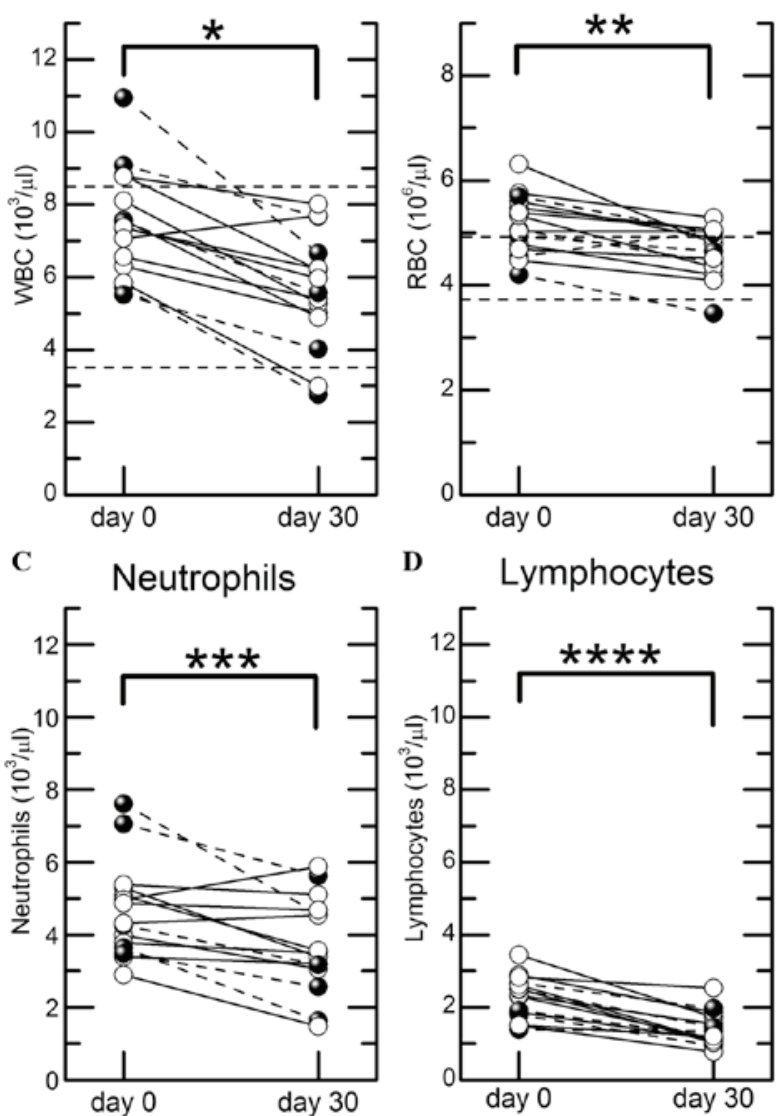

D Lymphocytes

E PLT
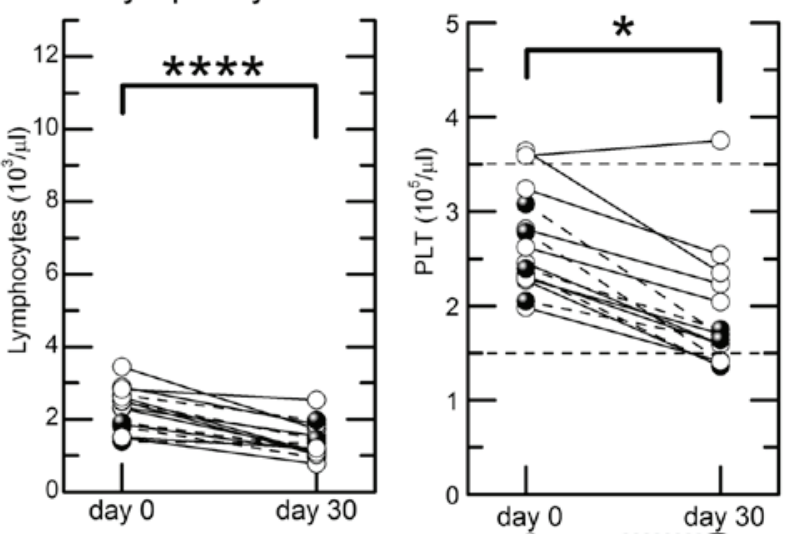

Figure 3. Evaluation of peripheral blood cell levels. The subpopulations of (A) white blood cells (WBC), (B) red blood cells (RBC), (C) neutrophils, (D) lymphocytes and (E) platelets (PLT) were calculated on days 0 and 30. Dotted line, normal range. White and black circles, patients administered 3.7 and $5.5 \mathrm{GBq}$, respectively. ${ }^{*} \mathrm{P}=1.22 \times 10^{-4},{ }^{* * *} \mathrm{P}=2.32 \times 10^{-3},{ }^{* * * * *} \mathrm{P}=2.14 \times 10^{-3}$ and ${ }^{* * * * * *} \mathrm{P}=6.10 \times 10^{-5}$ by Wilcoxon single-rank test. 

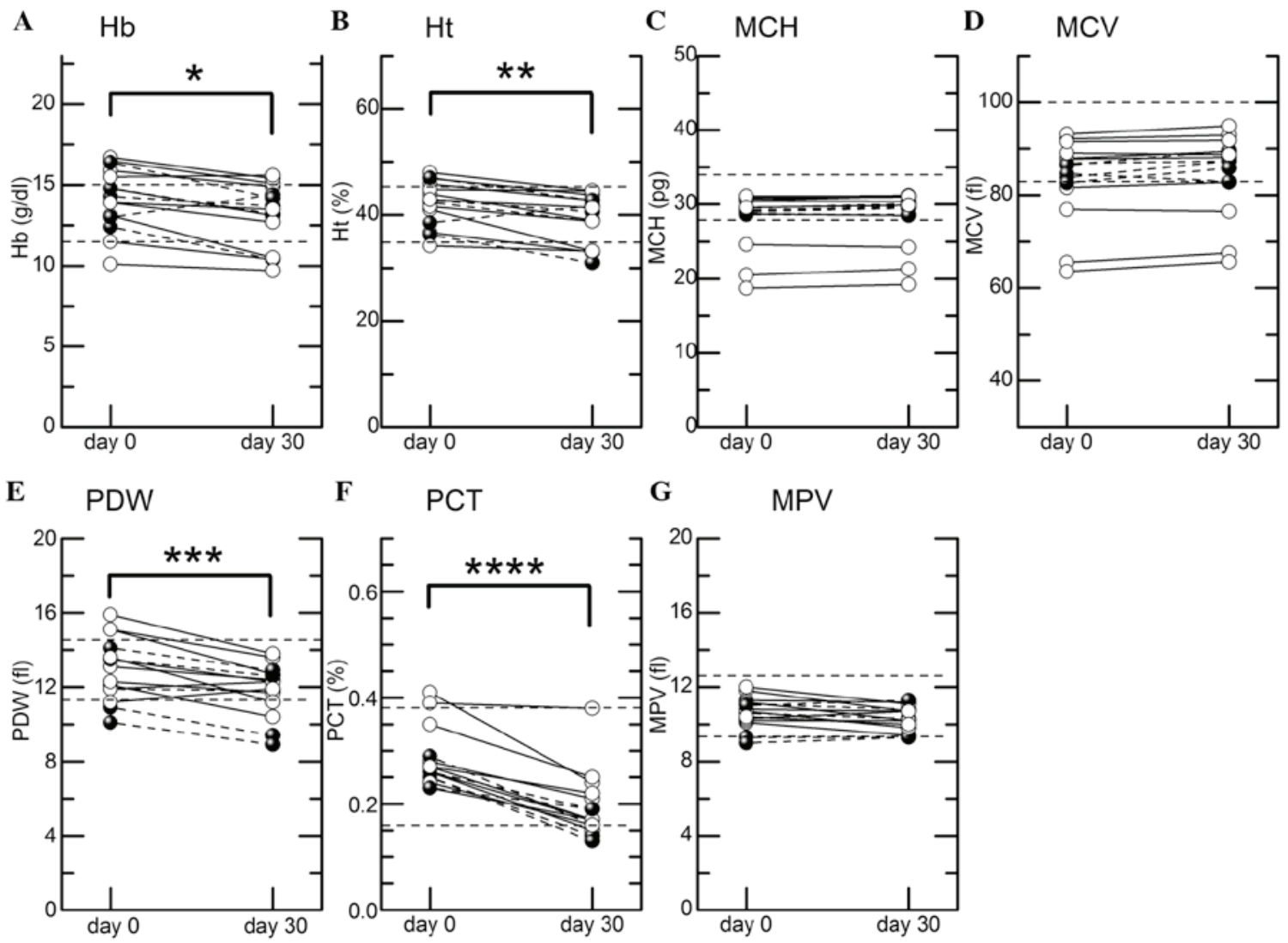

G MPV
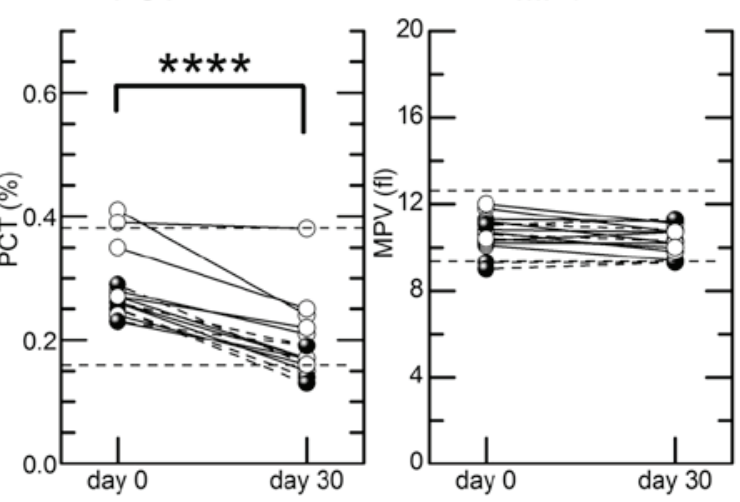

Figure 4. Functional analysis of peripheral blood cells. (A) Hemoglobin (Hb), (B) hematocrit (Ht), (C) mean corpuscular hemoglobin (MCH), (D) mean corpuscular volume (MCV), (E) platelet distribution width (PDW), (F) plateletcrit (PCT) and (G) mean platelet volume (MPV) were quantified on days 0 and 30. Dotted line, normal range. White and black circles, patients administered 3.7 and $5.5 \mathrm{GBq}$, respectively. ${ }^{*} \mathrm{P}=2.81 \times 10^{-3},{ }^{* * *} \mathrm{P}=1.53 \times 10^{-3},{ }^{* * * *} \mathrm{P}=1.10 \times 10^{-3}$ and ***** $\mathrm{P}=6.10 \times 10^{-5}$ by Wilcoxon single-rank test.

respectively, by day 30 compared to that on day $0(\mathrm{Hb}, 14.3 \mathrm{~g} / \mathrm{dl}$ and $\mathrm{Ht}, 42.8 \%$ ) (Fig. $4 \mathrm{~A}$ and B). As the levels of RBC, Ht and $\mathrm{Hb}$ were all significantly decreased, the mean corpuscular hemoglobin $(\mathrm{MCH})$ and the mean corpuscular volume (MCV) were estimated (Fig. 4C and D). These values were not significantly different between days 0 and 30. As regards PLT-related indices, the platelet distribution width (PDW) and the plateletcrit $(\mathrm{PCT})$ were decreased by 0.91 -fold $\left(\mathrm{P}=1.10 \times 10^{-3}\right)$ and 0.65 -fold $\left(\mathrm{P}=6.10 \times 10^{-5}\right)$, respectively, on day 30 , compared to day 0 (PDW, $13.1 \mathrm{fl}$ and PCT, 0.26\%) (Fig. 4E and F). The mean platelet volume value, an index of platelet maturation, was similar on days 0 and 30 (Fig. 4G). As noted for the other parameters, a strong individual variability in the response was observed, whereas there was no clear association between the extent of the effect and the applied iodine activity.

$M N$ frequency. In order to determine the genotoxic response in hematopoietic cells, the CBMN assay was performed using $\mathrm{CD} 45^{+}$cells. The purity of the $\mathrm{CD} 45^{+}$cell fraction was $\sim 70 \%$ (Fig. 5A and B). The radioiodine treatment generally led to an increase in $\mathrm{MN}$ frequency, although the effect was not evident in all the patients. Overall, a more significant increase in $\mathrm{MN}$ frequency was observed following the administration of $5.5 \mathrm{GBq}$ compared to that following the administration of $3.7 \mathrm{GBq}$ of iodine $(\mathrm{P}<0.05)$. However, this difference was mainly due to the results from two patients who received $5.5 \mathrm{GBq}$ of iodine.
Significantly negative correlations were observed between the induced frequency of MN and PLT, as well as PCT, but no such correlation was evident for thyroid-related hormones (PLT, R=-0.62637 and PCT, R=-0.70879, Table II).

The iodine retention time in patients who received 3.7 and $5.5 \mathrm{GBq}$ of the isotope was, on average, $39.7 \pm 3.9$ and $42.0 \pm 5.7 \% /$ day, respectively (Fig. 6).

\section{Discussion}

The aim of the present study was to analyze the effect of ${ }^{131} \mathrm{I}$ treatment of DTC patients on the hematopoietic system and determine the correlation with the treatmentefficacy, as assessed by thyroid-related hormone levels. After a 2-week thyroid hormone replacement period prior to ${ }^{131}$ I treatment (day 0), the fT3 and fT4 levels were found to be lower than normal (fT3, $2.30 \mathrm{pg} / \mathrm{ml}$ and fT4, $0.90 \mathrm{ng} / \mathrm{ml}$ ). However, resuming thyroid hormone replacement treatment following administration of ${ }^{131} \mathrm{I}$ resulted in an increase of these hormone levels to near-normal values (day 30; Fig. 2A and B). By contrast, the concentrations of TSH and Tg on day 0 were $\sim 20$-fold higher than normal (TSH, $5 \mu \mathrm{IU} / \mathrm{ml}$ and Tg, $32.7 \mathrm{ng} / \mathrm{ml}$ ), followed by a subsequent decrease to near-normal levels (Fig. 2C and D). In a specific system of thyroid-related hormones, it is known that TSH and thyrotropin-releasing hormone are affected by the negative feedback function of fT4/fT3 (16). In the present study, we confirmed the negative correlation between 
A

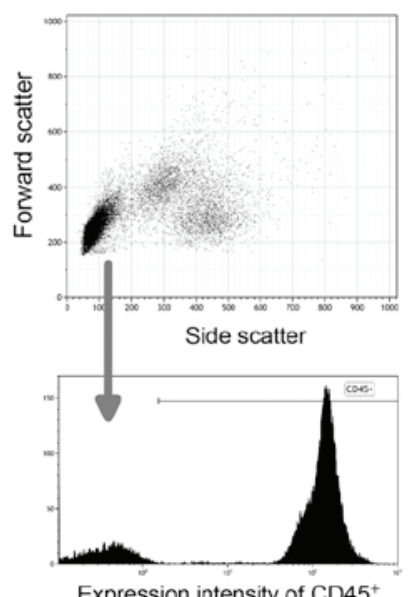

B

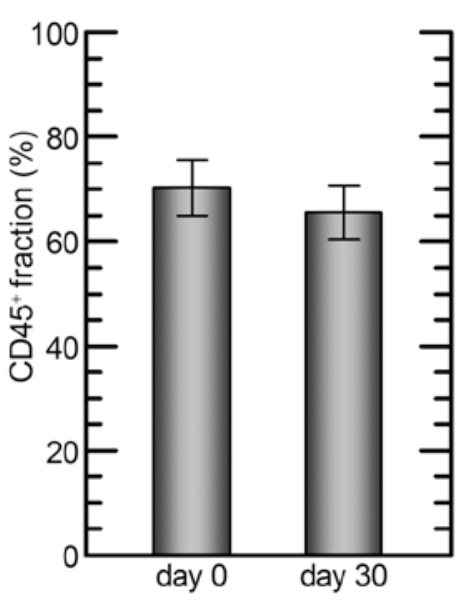

C

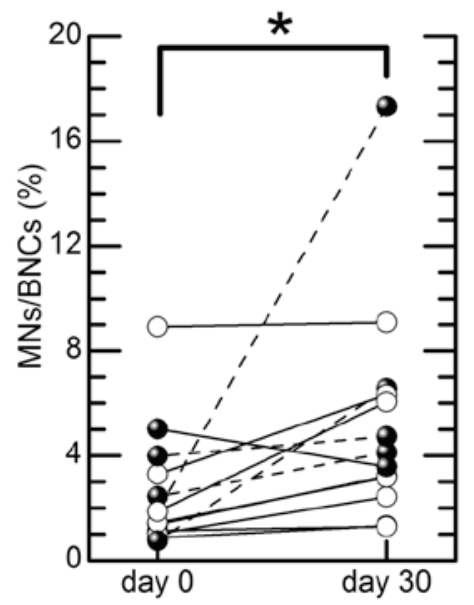

Figure 5. Micronuclei (MN) frequency in patient peripheral blood (PB) mononuclear cells. CD45 ${ }^{+}$PB mononuclear cells were analyzed by cytokinesis-block micronucleus assay on days 0 and 30 . The cell fraction was determined by (A) flow cytometry and (B) CD45 cells (white blood cell and progenitor cell fractions) were quantified. Subsequently, CD45 mononuclear cells were assayed and (C) the MN frequency in the binuclear cell (BNC) fraction was calculated. ${ }^{*} \mathrm{P}=3.42 \times 10^{-3}$ by the Wilcoxon single-rank test.

Table II. Correlation coefficient ratio of MN frequency vs. each peripheral blood change.

\begin{tabular}{lcc}
\hline Days 30/0 & P-value & Correlation coefficient \\
\hline Thyroid-related hormone & & - \\
MN vs. fT3 & 0.19083 & - \\
MN vs. fT4 & 0.24526 & - \\
MN vs. TSH & 0.08582 & - \\
MN vs. Tg & 0.15730 & \\
Leukocytes & & - \\
MN vs. WBC & 0.52907 & - \\
MN vs. RBC & 0.2387 & - \\
MN vs. Neu & 0.68079 & - \\
MN vs. Lym & 0.62861 & $-0.62637^{\mathrm{a}}$ \\
MN vs. PLT & 0.02199 & - \\
Leukocyte function & & - \\
MN vs. PLT & 0.10761 & - \\
MN vs. MCH & 0.20073 & - \\
MN vs. Hb & 0.36367 & - \\
MN vs. Ht & 0.41541 & $-0.70879^{\mathrm{a}}$ \\
MN vs. PDW & 0.5533 & \\
MN vs. MPV & 0.4757 & \\
MN vs. PCT & 0.00668 & \\
\hline
\end{tabular}

a'Statistical analysis was performed by Spearman's rank correlation test. MN, micronuclei; fT3, free triiodothyronine; fT4, free thyroxine; TSH, thyroid-stimulating hormone; Tg, thyroglobulin; WBC, white blood cells; RBC, red blood cells; Neu, neutrophils; Lym, lymphocytes; PLT, platelets; MCH, mean corpuscular hemoglobin; $\mathrm{Hb}$, hemoglobin; Ht, hematocrit; PDW, platelet distribution width; MPV, mean platelet volume; PCT, plateletcrit.

therapy-related changes in the levels of TSH and fT4/fT3. In addition, the levels of all $\mathrm{PB}$ cell fractions declined due to the toxicity of ${ }^{131} \mathrm{I}$ (Fig. 3).

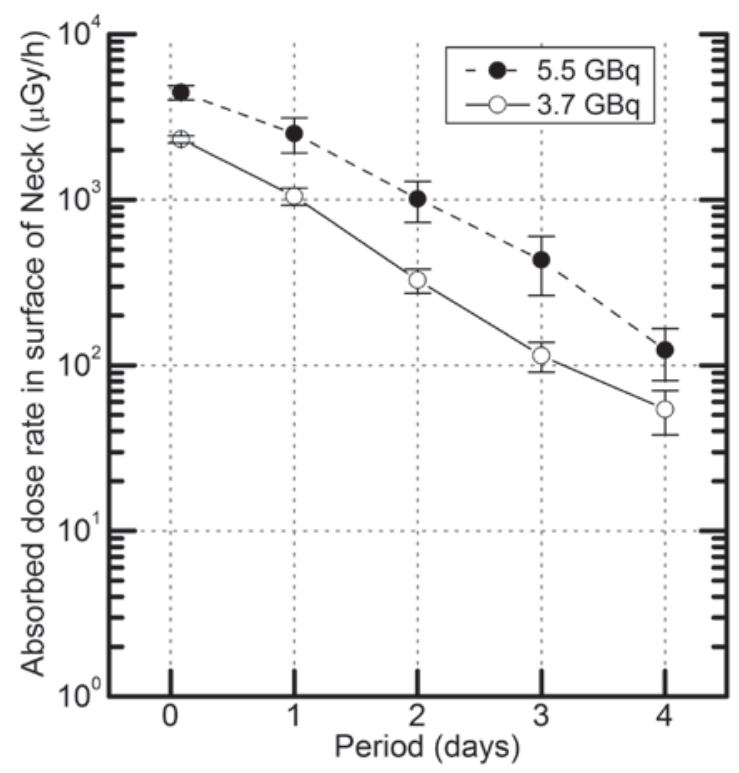

Figure 6. Retention rate of radioactive iodine in differentiated thyroid cancer patients. The absorbed dose rate in the air on the neck surface was measured using a $\gamma$-radiation survey meter in patients administered 3.7 (white circles) and 5.5 GBq (black circles) for 4 days following administration.

${ }^{131} \mathrm{I}$ emits energetic $\beta$ - $(606 \mathrm{keV}, 89.5 \%)$ and $\gamma$-radiation $(365 \mathrm{keV}, 81.7 \%$ ). It was demonstrated that granulocytes/monocytes are more radiosensitive compared to cells of the erythroid lineage, although an individual variability exists $(17,18)$. Vrndic et al $(19)$ reported that DTC patients treated with ${ }^{131} \mathrm{I}$ exhibited a significant increase in the early apoptosis of PB lymphocytes on day 7 after therapy. In addition to cell death, ionizing radiation activates cell cycle checkpoints $(20,21)$. Therefore, the reduction of cell counts in PB may be due to the apoptosis and/or suppression of hematopoietic clonogenicity. We have reported that megakaryocytic progenitors, also referred to as megakaryocytic colony-forming units (CFU-Meg), and mature megakaryocytes 
are radiosensitive; however, the sensitivity was observed to decrease at the terminal stages of megakaryocytic maturation, particularly as the megakaryocytes entered the proplatelet formation stage (22). Thus, it is suggested that the reduction of PLT on day 30 observed in the present study is attributed to the effect of radiation on the megakaryocytic maturation system.

The reduced levels of $\mathrm{RBC}, \mathrm{Hb}$ and $\mathrm{Ht}$ that were not accompanied by changes in the levels of MCH and MCV (Fig. 4A-D) suggest that the hematopoietic function, such as that of progenitor cells, was also modified. Maia et al (23) reported that reactive oxygen species induced by $\gamma$-radiation cause a physical modification in RBC viscosity and other membrane parameters. Dorgalaleh et al (24) reported that $\mathrm{MCH}$ and $\mathrm{MCV}$ in patients with hyperthyroidism and hypothyroidism were significantly lower compared to control values in healthy volunteers. Schindhelm et al (25) reported that fT4 (but not $\mathrm{TSH}$ ) was associated with erythrocyte indices (MCV and $\mathrm{MCH}$ ) in healthy controls, indicating that fT4 is involved in the regulation of erythropoiesis. The reduction of erythropoiesis in DTC patients may thus be specifically due to the effect of ${ }^{131}$ I rather than temporal hypothyroidism; however, further investigations on this phenomenon are required.

Alcelik et al (26) reported that PLT functions associated with thyroid function are mainly mediated by T4 and T3 and not by TSH or other factors secreted by the thyroid gland. Thus, it is possible that the decreased levels of PCT and PLT observed in the present study are associated with the effects of CFU-Meg, stimulated by thyroid hormones and ionizing radiation.

Similar retention rates of the two doses of ${ }^{131} \mathrm{I}$ activity administered were observed (Fig. 6). Thus, it may be hypothesized that the complete body dose received following the administration of $5.5 \mathrm{GBq}{ }^{131} \mathrm{I}$ was higher compared to that of $3.7 \mathrm{GBq}{ }^{131} \mathrm{I}$. However, the only difference in the biological effect between the two activities was observed at the MN level, albeit not in all the patients (Fig. 5). This result correlates with that reported by previous studies, in that the administration of ${ }^{131}$ I does not exert a strong effect on the extent of cytogenetic damage in PB lymphocytes (7-11). A possible explanation may be that iodine is specifically absorbed by the thyroid gland, leading to an exposure scenario that has partial body characteristics. It is known that the level of cytogenetic damage may serve as a biological dosimeter following whole-body exposure (27). An interesting observation is that MN levels correlate with PLT and PCT (Table II). Therefore, it is possible that a combination of these parameters may be used as a biomarker of exposure and, possibly, of sensitivity to radiation in DTC patients undergoing ${ }^{131} \mathrm{I}$ treatment following thyroid and lymph node surgery. Further analyses on a larger group of patients are required to confirm this hypothesis.

\section{Acknowledgements}

This study was supported by KAKENHI, a Grant-in-Aid for Young Scientists (B) (no. 25861054 S.M.), a grant from Hirosaki University Young Institutional Research (2013-2014), a grant from Hirosaki University Institutional Research (2012) and the Takeda Science Foundation to S.M. (2013). The funders were not involved in the study design, data collection and analysis, decision to publish, or preparation of the manuscript. We would like to thank the radio-nurse staff at the Hirosaki University School of Medicine and Hospital for their excellent technical assistance.

\section{References}

1. Sabra MM, Grewal RK, Ghossein RA and Tuttle RM: Higher administered activities of radioactive iodine are associated with less structural persistent response in older, but not younger, papillary thyroid cancer patients with lateral neck lymph node metastases. Thyroid 24: 1088-1095, 2014.

2. Prpic M, Dabelic N, Stanicic J, Jukic T, Milosevic M, et al: Adjuvant thyroid remnant ablation in patients with differentiated thyroid carcinoma confined to the thyroid: a comparison of ablation success with different activities of radioiodine (I-131). Ann Nucl Med 26: 744-751, 2012.

3. Lee SM, Lee JW, Kim SY, Han SW and Bae WK: Prediction of risk for symptomatic sialadenitis by post-therapeutic dual (131)I scintigraphy in patients with differentiated thyroid cancer. Ann Nucl Med 27: 700-709, 2013.

4. Bonnema SJ and Hegedus L: Radioiodine therapy in benign thyroid diseases: effects, side effects and factors affecting therapeutic outcome. Endocr Rev 33: 920-980, 2012.

5. Nagayama H, Ooi J, Tomonari A, et al: Severe immune dysfunction after lethal neutron irradiation in a JCO nuclear facility accident victim. Int J Hematol 76: 157-164, 2002.

6. Zarybnicka L, Sinkorova Z, Sinkora J, et al: Sensitivity of porcine peripheral blood leukocytes to gamma irradiation in vivo, in vitro and ex vivo. Int J Radiat Biol 87: 491-498, 2011.

7. Watanabe N, Kanegane H, Kinuya S, et al: The radiotoxicity of ${ }^{131}$ I therapy of thyroid cancer: assessment by micronucleus assay of B lymphocytes. J Nucl Med 45: 608-611, 2004.

8. Erselcan T, Sungu S, Ozdemir S, Turgut B, Dogan D and Ozdemir O: Iodine-131 treatment and chromosomal damage: in vivo dose-effect relationship. Eur J Nucl Med Mol Imaging 31: 676-684, 2004.

9. Ballardin M, Gemignani F, Bodei L, et al: Formation of micronuclei and of clastogenic factor(s) in patients receiving therapeutic doses of iodine-131. Mutat Res 514: 77-85, 2002.

10. Gutierrez S, Carbonell E, Galofre P, Creus A and Marcos R: Cytogenetic damage after 131-iodine treatment for hyperthyroidism and thyroid cancer. A study using the micronucleus test. Eur J Nucl Med 26: 1589-1596, 1999.

11. M'Kacher R, Schlumberger M, Legal JD, Violot D, Beron-Gaillard N, et al: Biologic dosimetry in thyroid cancer patients after repeated treatments with iodine-131. J Nucl Med 39: 825-829, 1998.

12. Vrndić OB, Milošević-Djordjević OM, Mijatović Teodorović LC et al: Correlation between micronuclei frequency in peripheral blood lymphocytes and retention of 131-I in thyroid cancer patients. Tohoku J Exp Med 229: 115-124, 2013.

13. Takahashi K, Monzen S, Eguchi-Kasai K, Abe Y and Kashiwakura I: Severe damage of human megakaryocytopoiesis and thrombopoiesis by heavy-ion beam radiation. Radiat Res 168: 545-551, 2007.

14. Monzen S, Yoshino H, Kasai-Eguchi K and Kashiwakura I: Characteristics of myeloid differentiation and maturation pathway derived from human hematopoietic stem cells exposed to different linear energy transfer radiation types. PLoS One 8: e59385, 2013.

15. EPR-BIODOSIMETRY 2011: Cytogenetic Dosimetry: Applications in Preparedness for and Response to Radiation Emergencies. IAEA, Vienna, 2011.

16. Fonseca TL, Correa-Medina M, Campos MP, et al: Coordination of hypothalamic and pituitary T3 production regulates TSH expression. J Clin Invest 123: 1492-1500, 2013.

17. Monzen S and Kashiwakura I: Radioprotective effects of (-)-epigallocatechin-3-gallate on human erythrocyte/granulocyte lineages. Radiat Prot Dosimetry 152: 224-228, 2012.

18. Takahashi K, Monzen S, Hayashi N and Kashiwakura I: Correlations of cell surface antigens with individual differences in radiosensitivity in human hematopoietic stem/progenitor cells. Radiat Res 173: 184-190, 2010.

19. Vrndić O, Milošević-Djordjević O, Djurdjević P, et al: Radioiodine therapy accelerates apoptosis in peripheral blood lymphocytes of patients with differentiated thyroid cancer. Neoplasma 60: 568-575, 2013. 
20. Hazawa M, Hosokawa Y, Monzen S, Yoshino $H$ and Kashiwakura I: Regulation of DNA damage response and cell cycle in radiation-resistant HL60 myeloid leukemia cells. Oncol Rep 28: 55-61, 2012.

21. Stiff T, Cerosaletti K, Concannon P, O'Driscoll M and Jeggo PA: Replication independent ATR signaling leads to G2/M arrest requiring Nbs1, 53BP1 and MDC1. Hum Mol Genet 17: 3247-3253, 2008.

22. Monzen S, Osuda K, Miyazaki Y, et al: Radiation sensitivities in the terminal stages of megakaryocytic maturation and platelet production. Radiat Res 172: 314-320, 2009.

23. Maia GA, Renó Cde O, Medina JM, et al: The effect of gamma radiation on the lipid profile of irradiated red blood cells. Ann Hematol 93: 753-760, 2014.
24. Dorgalaleh A, Mahmoodi M, Varmaghani B, et al: Effect of thyroid dysfunctions on blood cell count and red blood cell indices. Iran J Ped Hematol Oncol 3: 73-77, 2013.

25. Schindhelm RK, ten Boekel E, Heima NE, van Schoor NM and Simsek S: Thyroid hormones and erythrocyte indices in a cohort of euthyroid older subjects. Eur J Intern Med 24: 241-244, 2013.

26. Alcelik A, Aktas G, Eroglu M, et al: Platelet function in euthyroid patients undergoing thyroidectomy in women. Eur Rev Med Pharmacol Sci 17: 2350-2353, 2013.

27. Pilli T, Brianzoni E, Capoccetti F, et al: A comparison of 1850 $(50 \mathrm{mCi})$ and $3700 \mathrm{MBq}(100 \mathrm{mCi})$ 131-iodine administered doses for recombinant thyrotropin-stimulated postoperative thyroid remnant ablation in differentiated thyroid cancer. J Clin Endocrinol Metab 92: 3542-3546, 2007. 